\title{
Study on Dissemination of Folk Linguistic Cultural Symbols and Building of National Cultural Self-confidence
}

\author{
LEI Qian-qian
}

Chongqing Vocational Institute of Tourism, Qianjiang, Chongqing, China

\begin{abstract}
Keywords: folk linguistic cultural symbols; structural interpretation; dissemination; national cultural self-confidence
\end{abstract}

\begin{abstract}
The folk linguistic cultural symbols being its research object, this study defines and sorts out the scope of the folk linguistic cultural symbols from the theoretical point of view, interprets them structurally with examples, and also probe into the dissemination function, disseminator and dissemination path of the folk linguistic cultural symbols. It aims to make the mass groups have a clear understanding of the folk linguistic cultural symbols and then commit to the dissemination of the folk linguistic cultural symbols at home and abroad, so as to promote the traditional Chinese folk linguistic culture, and to build the cultural self-confidence of the Chinese nation.
\end{abstract}

\section{传播民俗语言文化符号, 构建民族文化自信 一以重庆民族地区为例}

\author{
雷乾乾 \\ 重庆旅游职业学院, 黔江区, 重庆直辖市, 中国
}

关键词：民俗语言文化符号；结构解读；传播；民族文化自信

中文摘要: 本文以民俗语言文化符号为研究对象, 从理论的角度对其进行界定并梳理民俗语 言文化符号的范围, 并结合实例对其结构性解读, 最后还探讨民俗语言文化符号的传播功能、 传播者、传播路径等, 以使大众群体对民俗语言文化符号有清晰的认识并致力于民俗语言文 化符号在国内外的传播，弘扬中国传统民俗语言文化、构筑中华民族文化自信。

1. 引言

符号是文化的载体，文化的创造和传承是以符号为媒介的。在文化与语言世界图景中,民 俗语言作为一种特殊的语言符号、文化符号和象征符号, 是一种复合型的文化现象。中国特色 文化，源自于中华民族五千多年文明历史所孕育的中华优秀传统文化。民俗语言文化符号既 具有典型的民族性又具有高度的凝聚作用。人们在对于身所处群体或地域的民俗语言文化符 号进行辨别、学习、记忆以及认知等过程中激发强烈的文化自豪感与对民族文化的认同感, 从而有效地构建本民族文化身份。

重庆是中国唯一辖有民族自治地方的直辖市, 辖 4 个自治县、1 个享受民族自治地方优 惠政策的区（黔江区）、14 个民族乡。重庆人口以汉族为主体，少数民族人口占重庆市人口 的 $5.8 \%$, 以土家族、苗族为主，此外有回族、满族、彝族、壮族、布依族、蒙古族、藏族、 白族、侗族、维吾尔族、朝鲜族、哈尼族、傣族、傈僳族、低族、拉祜族、水族、纳西族、 芫族、仡佬族等少数民族。本文将从重庆民族地区的实际出发, 解析民俗语言文化符号, 并 探讨传播中华民族优秀传统民俗语言文化、坚定民族文化自信的重要路径。 


\section{2. 相关理论：民俗语言文化符号}

\section{（一）民俗与文化、语言与文化}

“民俗”与“语言”，作为两种社会现象，二者都是“文化”的重要组成要素。文化的基本要 素可涵盖“知识、信仰、艺术、道德、法律、风俗、技能、社会关系、社会组织、价值观念、 行为规范和模式、语言符号、人造物品、物品形式” 等多种成分, 从总体上可概括成以下四类: 物质要素、精神要素、语言和象征符号要素、规范体系。其中, 语言、姿势、表情、动作、 声音、图形、标志等都属于语言和象征符号要素范围。民俗作为文化的重要组成之一，其经 典定义由曲彦斌 (1992)提出,即“民俗,亦即民间风俗习惯,是人类社会长时期相沿积久而形成的 习俗惯制、礼仪、信仰、风尚等民间文化传承现象的总和,是经群体、社会约定俗成并流行、 传承的民间文化模式”。语言也与文化紧密相关, 表现为: 语言是文化的组成部分; 语言是文 化的标志; 每种语言都可成为与之密切相连的文化之“象征”。

\section{（二）语言与民俗}

语言是民俗事项的主要组成部分。曲彦斌（1989）曾写道“在人类社会中，民俗是伴随着 语言的产生而逐渐沉积形成的。语言是思维、意识存在的形式, 当然也是民俗的主要存在形 式。”社会学家将民俗分为四类：物质生活民俗、社会生活民俗、精神生活民俗、语言民俗。 人类学家兼语言学家爱德华・萨不尔(Edward Sapir),对北美印第安人的语言与文化做过深入的 调查研究后, 认为“语言也不脱离文化而存在, 就是说, 不脱离社会流传下来的、决定我们生活 面貌的风俗和信仰的总体”。现代语言学奠基人索绪尔((Ferdinand de Saussure),同样指出:“一个 民族的风俗习惯 常会在它的语言中有所反映, 另一方面, 在很大程度上,构成民族的也正是语 言。”

语言又是民俗的载体。从总体上说，语言承载民俗“或是语言材料直接反映民俗,或是语 言体系折光反射民俗”（马学良, 李耀宗：1994）。具体来讲, 语言单位或源自民俗, 或陈述 民俗，或旁涉民俗，或夹带涉俗语词，又或以集合形式反射民俗惯制或风貌。

所以，语言民俗具有双重属性。正如钟敬文先生在其主编的《民俗学概论》所谈: “语言 既是民俗的一种载体，同时也是一种民俗现象，不能将二者分开或并列起来，要用一般民俗 文化的基本特征去考察语言现象等”。对语言现象的民俗学研究已成为国内外众多学科以及交 叉学科的一个研究整体, 但是各自的研究侧重点不同。比如, 语言学注重民俗语言的形式构 造, 民俗学把民俗语言当作民间文化现象进行整体性把握, 更加注重考察与语言形式紧密关联 的生活情境和民众精神。

\section{（三）民俗语言文化}

与生俱来，“语言、民俗、文化”三者就彼此交融、相互依存。“语言是民俗存在和传承的 主要载体, 而民俗反映语言变迁, 在一定程度和范围上影响、制约着语言与言语活动, 两者均 属人类社会的原生文化形态 (肖建华，2010)”。语言与民俗在原发性“共同的双向涵化运动过 程”中相互侵染, 涵化成民俗语言文化形态, 并在人类文化历史进程中继续变异与发展。综上 分析，语言、民俗、文化，三者之间的关系，如图 1 所示:

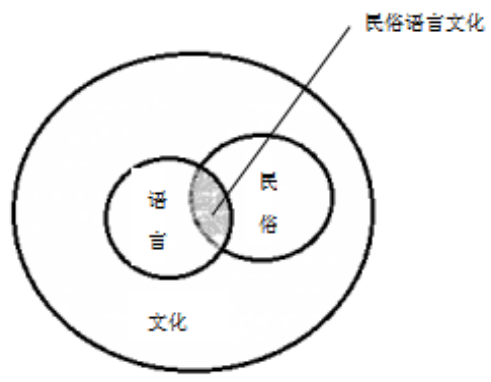

图 1. 语言、民俗、文化的关系图 


\section{（四）符号学视角下的民俗语言文化}

从亚平（2017）说到“在文化与语言世界图景中，民俗语言作为一种特殊的语言符号、文 化符号和象征符号，是一种复合性的文化现象”。毫无疑问，在人类符号活动中，民俗语言文 化符号占有特殊的地位。民俗语言文化符号作为人类传统文化的重要象征性标记，作为传承 民族文化的重要载体，在人类文明史上承载了大量的文化信息, 所以从符号学的角度去解读 这个充满了民俗语言文化符号的世界，揭示民俗语言文化信息具有重要的时代意义。

德国当代哲学家恩斯特·卡西尔说,人是进行符号活动的动物, 特定符号推动着特定文化的 生成与发展。卡西尔所著《人论》给我们以下三点启示: “符号开创了文化”、“符号重建了文 化”、“符号传播着文化”。作为多学科汇合的产物, 对符号学的研究主要有以下四种模式作为 理论支撑: 语言学模式、逻辑-修辞学模式、“文化符号论”模式、“语言中心马克思主义”模式。 人类文化的各个部门都涉及意义活动, 因此都是符号学的用武之地。符号学为民俗文化研究 提供了一个理论视角和一种研究方法。人类社会的历史过程, 从符号学的视角说, 就是一种 不断生产和消费文化符号的过程。符号就是文化, 没有符号文化, 文化也就不能“传承、交流、 储存和增值”。本研究属于“文化符号论”模式，从符号学领域对民俗语言文化的研究展现了符 号学发展的重要战场所在，也体现了在各种文化领域中的应用符号学研究趋势。

\section{3. 民俗语言文化符号的解读}

\section{（一）民俗语言文化符号的类别与范围}

曲彦斌 (1992) 认为，民俗语言文化以民俗语言和民俗语言现象为主体，具体涵盖“俗语”、 “民俗语汇”、“以言语习俗、民间口头语言艺术为主民俗语言文化形态”等。李新国,於涵 (2012) 把民俗语言等同于语言民俗, 并将其界定为“以言语习俗和民间口头语言艺术为主要类型的民 俗语言文化形态”，主要包括神话、传说、故事、歌谣、谜语、浐语、俗语、俚语、方言土语 等民间文学。这一概念将“语言民俗”概念等同于“民俗语言”，未将民俗语言与民俗语言现象 作区分。其实, 二者是截然不同的: 前者主要是语言材料, 后者主要是规律性、模式化的行为 方式。

本研究倾向于曲彦斌教授的观点，将“民俗语言文化”看作“民俗语言”与“民俗语言现象” 的统一体。“民俗语言”是在具体文化情境下发生的民众行为与民俗活动, 是直观的、活生生 的”。“民间语言现象”是在特定的文化背景下民众所进行的语言活动,是一种模式化的、复合性 的文化现象。我们不能忽视民俗语言现象，只谈民俗语言。民俗语言现象包括了类型化的语 言行为及与之关联的生活情境,和支配语言行为, 并关注民众精神或民俗心理, 使我们更全面 地解读与认识民俗语言的意义、功能。

在前人研究基础上，本文所界定的民俗语言文化符号为：经约定俗成、获得广泛认知、 习用的涵化有民俗要素的“语言材料”与民俗语言、民俗语言现象的统一体。它包括三个层面: 语言形式、语言行为和与之关联的民众精神状态, 语言民俗研究就是这三个层面的整体研究, 以第一层面为线索, 以后两个层面为重点,同时这三个层面的研究不能脱离民众的生活情境. 具体来讲，本文在研究重庆民族地区的民俗语言文化符号具体案例时所界定的符号范围与类 别, 如表 1 所示:

表 1. 民俗语言文化的构成

\begin{tabular}{|c|c|c|}
\hline $\begin{array}{l}\text { 民 } \\
\text { 俗 }\end{array}$ & \multirow{2}{*}{$\begin{array}{l}\text { 民俗 } \\
\text { 语言 }\end{array}$} & $\begin{array}{c}\text { 俗语 } \\
\text { (口语性成语、谚语、格言、歇后语、惯用语、俚语等) }\end{array}$ \\
\hline $\begin{array}{l}\text { 语 } \\
\text { 言 } \\
\text { 文 }\end{array}$ & & $\begin{array}{c}\text { 民俗语汇 } \\
\text { （方言土语词、俗语词、秽语、䍗语、禁忌、口彩语、民间秘密语、民间流行习俗、 } \\
\text { 口头禅、非隐语性行业习惯语等） }\end{array}$ \\
\hline
\end{tabular}




\begin{tabular}{|c|c|c|}
\hline 化 & & 言语习俗 \\
& 民俗 & (副语言习俗、称谓语俗、言语风尚、城乡等地域或群体性语俗、 \\
& 语言 & 人名、绰号等） \\
\cline { 3 - 3 } & 现象 & $\begin{array}{c}\text { 民间口头语言艺术 } \\
\text { (神话、传说、故事、歌谣、谜语、说唱、咒语等) }\end{array}$ \\
\hline
\end{tabular}

\section{（二）民俗语言文化的符号化过程}

构成文化的整个社会行为领域，不管是语言的还是非语言的，实际上都表现为一种类似 语言的模式进行“编码”活动。列维·斯特劳斯曾在其著作《结构人类学》中指出, “文化领域 中如亲属, 食物, 烹杄, 婚姻仪式, 政治的意识形态等都可以看作是一种巨大的语言符号系 统”。与语言符号系统一样，客观存在的民俗语言文化符号系统也有一定的较为固定的结构, 遵循着一定的规律。乌丙安（2000）指出“民俗的符号化过程实际上是由表现体、对象、背景 性的概念这三个要素的关系之间作用而成的规律”。具体来讲就是:民俗符号做为民俗表现体， 是用某一个民俗事物做代表,来表现或表示它所能表示的对象,最后还要由相应背景中的人们 对它做出公认的解释,也就是指明它的含义或概念。民俗语言文化的符号化过程也是有规律性 的。如果用重庆民族地区的布依族婚姻家庭的民俗语汇为例, 用上述的民俗符号三要素结为 “三位一体”的逻辑规律来解读的话,那便是以下的形式:

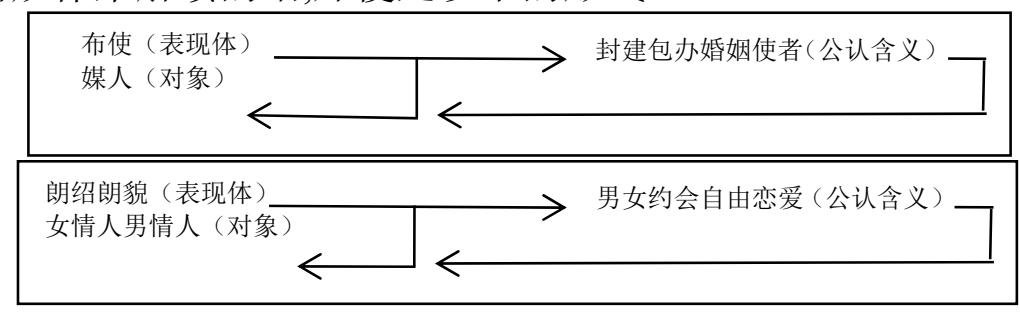

图 2. 民俗语言文化符号“三位一体”的逻辑规律示例

在图例 2 中, 言语代码“朗绍朗貌”是布依族民俗语言文化的表现体, 当地汉语称为“赶表”、 “坐表”、“玩表”、“打老表”、“闹门墙”等等。它们在布依族秘民俗共同体中指称的对象是相互 约会的男女青年，具体自由恋爱的象征含义，并为俗民所共识。“布使”这一民俗符号表现体， 用来标志媒人，在传统民俗背景下象征着男女双方父母找人撮合婚事的婚姻习俗。需要注意 的是，民俗语言与民俗语言现象的形成与发展受到严格的民俗规律所制约、所支配。，所以 在对民俗语言文化符号的公共含义进行解读时要置于一个民俗共同体之中,要熟悉该符号所 恪守的民俗传统规则。

\section{（三）民俗语言文化符号的基本结构}

民俗语言文化信息的交流过程，实际上演变为两个方面的相互作用。一方为: 表现体 (要 素一）；另一方面为：所表现对象（要素二）、相应背景中的含义或概念（要素三）。从此 层面上理解，民俗语言文化符号的基本结构为两个元素：“民俗语言文化表现体”与“所表现的 具体民俗对象与抽象民俗含义或概念的结合”。任何民俗语言文化事象, 离开了这两个最基本 的元素,将不会属于“民俗事象”范畴。

民俗语言文化符号具体两个基本元素：“指符”与“所指”。“指符”（或“能指”、“形符”）是 指“某种民俗语言文化信息在传递给俗民时，俗民接收到该信息时,立即收取到的、可以直观 或直感的的、形象的(或影像的、具象的)东西”。民俗语言文化的“指符”可表示或指示某种该 符号所要传送的那个对象和含义。与俗民们感受到一个个或一幅幅的民俗语言文化事象时,民 俗语言文化符号的第二个元素便出现了。“所指”（或“意符”）指的是“与某个或某些物象密切 联系,由俗民所推知、所理解或所联想的民俗语言文化含义或概念”。简言之，“所指”就是民俗 语言与民俗语言文化现象文化被解释的民俗内涵或外延。只有完成对“能指”与“所指”两方的 识读与解读，民俗语言文化符号传送民俗信息的任务才算完整地完成。“能指”与“所指”合二 
为一才构成了完整的符号。

民俗语言文化符号的产生,是民俗语言、民俗语言文化现象的表现形象（形符）,和所表现 出的民俗概念（意符）统一。图 3 可形象地说明民俗语言文化的“指符”和“所指”两元素统一 而成民俗语言文化符号。图 3 中, “白虎”二字组成一个语言符号, 当土家俗民听到“bai hu”字 音时, 最后联想到的不是“某一类的虎”, 而是崇高的祖先形象。土家族为古代巴人之后裔, 自称“比兹卡”。“比兹”是巴人对白虎的称呼。白虎是“指符”,“所指”则是祖先,“指符”与“所指” 共同构成一个象征着祖先崇拜的民俗语言文化符号。

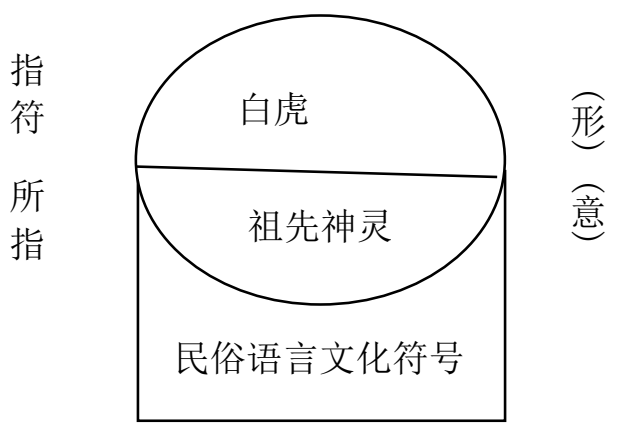

图 3. 民俗语言文化符号基本结构示例

\section{4. 民俗语言文化符号的传播}

\section{（一）民俗语言文化符号的传播功能}

符号孕育文明, 传承文明, 并传播文明。符号具有传播功能。人们在传播过程中运用符 号传达信息, 这是一个从表达到理解的过程, 也就是从符号编码到符号解码的过程。表达者 把信息符号化, 以符号的形式呈献给理解者, 这就是编码的过程; 理解者把符号形式还原为 信息的过程就是解码的过程。

相比于一般符号, 民俗语言文化符号传播功能更为明显：对内而言，拥有相同民俗语言 文化背景的人们对民俗语言文化符号有相近的记忆而产生共鸣, 对外而言, 拥有不同民俗语 言文化背景的人们由于好奇的心理而交往互动, 互相学习、逐渐达成理解, 形成共识。在某 一民俗共同体的约定俗成前题下, 民俗语言文化符号可作为媒介, 在个体与个体、群体与群 体以及代际之间传递符号, 从而实现人与人之间的思想沟通与情感交流。具体来讲, 此传播 过程为: 信息表达者把民俗语言指称对象进行编码, 使之成为具有民俗语言文化内涵意义的 符号, 并通过一定的手段进行传播, 再通过解码获取意义。

人们通过符号来表达思想、传递意义，而国家、社会、民族等层面的行为体则通过符号 来展现自己的文化、理念、身份和形象。当今时代, 符号已成为跨区域、跨民族、跨国家交 往的重要媒介。通过一连串具有强代表性的民俗语言文化符号所指与更深层次的意指, 在本 国和国际受众之间建立可沟通的桥梁, 通过各式各样的符号传达出国家传统文化, 让观者通 过民俗语言符号对国家有整体的、深刻的认识, 在文化自信中传播国家形象、增强中国文化 的国际话语权。

\section{（二）民俗语言文化符号传播中的“误读”}

编码与解码共同构成了符号信息化传播的过程。在实际上，在不同的时间和空间，某一 具体的符号可能有不同的指涉物; 而且, 在相同的时间与空间, 不同的符号可能指涉同一事 物。所以, 符号极其复杂。这也是造成符号误读的重要原因之一。另外, 符号的任意性、模 糊性、抽象性、多变性等特点, 也容易在传播中造成意义差别, 导致误读甚至对立。

在中国民俗语言文化符号的对外传播中, 误读的现象依然很多。比如, 在重庆地区土家 族文化传播中, 一种非常突出的误读现象就是：吐司嗜杀。在民俗语言文化资料, 特别是民 
俗语言文化现象中, 吐司常常被描述成刑法严酷、杀人成性的㓣子手形象。其实, 很多地区 的吐司沿袭了百年，且没有变更吐司族系，甚至在“改土归流”中主动“献土归流”。土家族民 歌的误读现象也表现得非常突出。许多民歌经历多年的流传后，一些重要的细节被模糊、扭 曲，人们很难清晰地看到最初的面貌，甚至存在民歌作者的“创造性误读”现象。这种种误读 现象, 毫无疑问地会影响民俗语言文化的传承, 影响不同人士对该地区民族文化的理解与认 同。

\section{（三）民俗语言文化符号的传播途径}

民俗语言文化符号的传播群体有族内人士与族外人士之分。

各民俗共同体内部的普通成员，作为族内人士的一大群体，是集体意义上的传播者。他 们直接参与民俗语言活动, 学习祖辈传递下来的民俗语言, 并亲身感受到各类民俗语言现象, 然后以族群的名义共同对民俗语言进行固定、演化，并开展代际传承。族内人士，还包括个 体意义上的传播者, 主要是本民族的文人学士、学者等, 通过神话、传说、故事、歌谣、谜 语、说唱等民间口头语言艺术向外部社会传播各个层面的信息。

族外人士，即传播中的外来者，是一个庞杂的群体。现代社会，该群体主要有两类： 众多的大众媒体工作人员。该类人员的工作往往会形成大量反映文化的民俗语言文本，这些 文本在很大程度上成为外界感知民俗文化风情的基础性来源，而且外界往往以传媒中的民族 形象作为认知该民族的基本标准。（2）在特色民族地区旅游业开发中，越来越多的游客进入 该地区，实地了解该地的各种民俗语言文化，然后通过人际传播、大众传播等途径，向外界 传达他们对该民族的印象。这在客观上也达到了传播的目的。无论属于这两类人员中的哪种, 族外人士对民俗语言文化的传播都是以外来者的眼光，理解、领悟各种民俗语言文化，再将 其在更广的范围内传播，使之在社会上产生巨大反响。这就需要外来者作为民俗语言文化传 播者要以平和的心态、视角看待风俗, 尽可能减少因对民俗的来历、历史渊源等理解不透彻 而造成的民俗语言文化信息的误读，更不能将民族文化视为“他者”，将其语言民俗视为“异 俗”。

在中国文化“走出去”战略的大背景下，重庆应该积极响应国家战略要求，重点打造辖区 4 个自治县、1 个享受民族自治地方优惠政策的区（黔江区）、14 个民族乡的民俗语言文化符 号特色，使之成为重庆文化“走出去”的急先锋。一般来讲，民俗语言文化符号的对外传播从 形式和属性上, 可以分为文化外交和文化贸易两种基本形式。因此, 重庆民族地区民俗语言 文化符号的对外传播，要充分利用文化外交和文化贸易这两种形式，通过报纸杂志、广播电 视、互联网等媒体，利用政府外交、公共外交等传播渠道，借助文化演出、影视交流、图书 展示、艺术展览等形式和各类国际性文化博览会、文化产品交易会以及国际性文化论坛等平 台，全面展示重庆民俗语言文化符号; 培养和打造一批有利于重庆地域形象和中国国家形象 建构的、生产标识性的文化产业，创设文化品牌，开展文化对外贸易，为世界提供具有重庆 风格、代表重庆地域形象的民俗语言文化产品, 为展示重庆地域形象提供丰富的媒介和平台。 其中，除了官方交流以外，尤其要重视民间交流，使官方交流和民间交流相互促进，形成重 庆民俗语言文化符号对外传播的合力。同时，制定民俗语言文化符号对外传播的反馈、评估 和纠正机制，提高传播的针对性和有效性。传播过程中，尤其要注重深入挖掘民俗语言文化 符号的意义和功能, 借助现代文化艺术形式和现代文化传播手段, 进行现代性诠释, 淡化意 识形态色彩, 在不断地创新和超越中实现重庆地域乃至整个中国民俗语言文化符号的现代性 重构，使国际社会增进对中国的了解，增强其对中国“和平发展、求同存异、负责任大国”国 家形象的认同。

民俗语言文化的对外传播从符号学的视角来看，该传播过程是在同一符号意义系统下的 编码、译码 (解码) 过程; 编码与译码是约定俗成的, 在特定的群体、特定的文化中流通, 而一旦跨越这个系统，就是跨文化传播的过程。跨文化传播中，人们对民俗语言文化符号的 理解往往容易出现歧义和误解，这就需要传受双方运用恰当的途径与方法来传递信息，在揭 
示文化差异的过程中展现文化的意义。

\section{5.小结}

从符号学的视角对重庆民族地区的民俗语言文化的符号类别、符号构成、符号意义、符 号价值等进行深度解读, 从最直观的视觉角度加强对地方传统民俗语言文化的审视, 这将有 助于国际人士对中国民俗语言文化和中国传统文化有更准确的认识, 增强中国文化软实力, 强化民族文化自信。但是, 民俗语言的符号化是一个动态过程, 民俗语言文化会在历史变革 中被强化或者消亡。如何从当前国际环境和国家战略目标要求出发, 在对外传播中选择合适 的民俗语言文化符号, 跨越文化交流异质性障碍, 在不断创新中实现中国语言文化符号的现 代化重建, 使国内外人士对中国传统民俗有更全面的认识。这是本人后续研究与努力的方向。 民俗语言文化研究既要有语言学的专业知识, 又需要民俗学、文化学等的素养, 因此其建设 与发展难度很大, 亟待学术界同行的不断努力。

\section{致谢}

本文是重庆市教委人文社科规划项目“重庆民族地区民俗语言文化符号的建构与传播” （编号：19SKGH286）、重庆旅游职业学院校级课题 “文化自信视阈下土家族织锦文化符号 的建构与传播”（编号：XJkt-2018-01）的研究成果。

\section{References}

[1] Qu Yan-bin. New Views on Folklore Linguistics[J]. Folklore Studies,1992(01):14-23.

[2] Qu Yan-bin. Folklore Linguistics[M]. Shen Yang City: Liaoning Education Press, 1989:9,15.

[3] Zhong Jing-wen. The Tradition of Folk Language Research since the May 4th Movement and the Development of Language Folklore in the New Period[J]. Northwestern Journal of Ethnology,2002(02):5-13.

[4] Ma Xue-liang, Li Yao-zong. On Folk Language[J]. Journal of Minzu University of China (Philosophy and Social Sciences Edition),1994(05):70-82,38.

[5] Zhong Jing-wen. An Introduction to Folklore[M]. Shanghai: Shanghai Literature and Art Publishing House, 1998:198.

[6] Xiao Jian-hua. A Preliminary Study of Folk Language [M]. Beijing: China Social Press, 2010.

[7] Wang Mingyu, Song Yao. 20 years of Semiotics in China [J]. Foreign Languages, 2003, (1).

[8] Cong Ya-ping. A Preliminary Research on Russian and Chinese Folk Languages from a Comparative Perspective[J]. Foreign Language Research in Northeast Asia, 2017,5(03): 9-12.

[9] (German) Cassirer (E.). Human Theory [M]. Translated by Ganyang. Shanghai: Shanghai Translation Publishing House, 2004.

[10] Li Xin-guo, Yu Han. On the Construction and Function of English Folklore Linguistic Context from a Cultural Perspective [J]. Journal of Huaibei Normal University (Philosophy and Social Sciences Edition), 2012, 33 (04): 107-111.

[11] Levi Strauss. Structural Anthropology [M]. Translated by Zhang Zu-jian. Beijing: Renmin University Press, 2005.

[12] Wu Bing-an. Principles of Folklore [M]. Shenyang: Liaoning University Press, 1985. 
[13] Wu Bing-an. Entering the Symbolic World of Folklore - Folklore Symbolism [J]. Jiangsu Social Sciences, 2000 (03): 39-53.

[14] Xu Ji-guang, Li Ying, Xu Ji-hua. Tufeng Bayun: Tujia Communication Research [M]. Shanghai: Fudan University Press, 2016.

[15] Meng Xiang-fei. Communication of China's National Image and Cultural Symbols [M]. Beijing: Wuzhou Communication Publishing House, 2017. 